\title{
ANÁLISE DO BALANÇO HÍDRICO CLIMATOLÓGICO DO SISTEMA AQUÍFERO GUARANI, EM SUA ÁREA DE AFLORAMENTOS NO ESTADO DE SÃO PAULO
}

\author{
SANTOS, Maurício Moreira - mmsantos.geo@gmail.com \\ Universidade Tecnológica Federal do Paraná UTFPR / Londrina \\ CHANG, Maria Rita Caetano - mrchang@rc.unesp.br. \\ Dep. Geologia Aplicada- IGCE / UNESP - Universidade Estadual Paulista \\ KIANG, Chang Hung - chang@rc.unesp.br \\ Dep. Geologia Aplicada- IGCE / UNESP - Universidade Estadual Paulista
}

\begin{abstract}
RESUMO. A pluviosidade e a temperatura do ar representam atributos fundamentais na análise dos climas tropicais, refletindo a atuação das principais correntes de circulação atmosférica e fornecendo subsídios essenciais para a avaliação do balanço hídrico regional. A partir da análise de dados de precipitação e temperatura disponíveis na área de afloramento do Sistema Aquífero Guarani (SAG) no estado de São Paulo, procedeu-se à determinação do balanço hídrico regional e ao cálculo da recarga direta por precipitação. Os dados pluviométricos e de temperatura utilizados pertencem à série histórica de 1982 a 1995, obtidos junto ao Departamento de Água e Energia Elétrica do Estado de São Paulo (DAEE). Constatou-se que as taxas pluviométricas na área de afloramento das formações geológicas constituintes do SAG são da ordem de $1400 \mathrm{~mm} / \mathrm{ano}$ a $1600 \mathrm{~mm} / \mathrm{ano}$, com média para o período levantado de $1570 \mathrm{~mm} / \mathrm{ano}$, sendo o excedente hídrico estimado em um volume total médio de $604 \mathrm{~mm} / \mathrm{ano}$, possibilitando o cálculo da reserva ativa do SAG em aproximadamente $4,4 \times 10^{8} \mathrm{~m}^{3}$ /ano.
\end{abstract}

Palavras-Chave - Balanço Hídrico; Sistema Aquífero Guarani; Recarga de Aquífero; Reserva Ativa.

THE INFLUENCE OF PRECIPITATION AND TEMPERATURE IN THE WATER BALANCE OF GUARANI AQUIFER SYSTEM, IN YOUR OUTCROPS ZONE IN THE STATE OF SÃO PAULO

ABSTRACT. The Rain precipitation volume and temperature are fundamental attributes in the analysis of tropical climates, reflecting the performance of the main flow of atmospheric circulation, and supporting the calculation of the regional water balance. The analysis of temperature and precipitation data available in the outcropping area of Guarani Aquifer System (SAG) in São Paulo state allowed determining the regional water balance and the volume of the recharge by meteoric water. Precipitation and temperature data belong to the historical series from 1982 to 1995 obtained from Departamento de Água e Energia Elétrica do Estado de São Paulo (DAEE). The results showed that annual precipitation in the SAG outcropping area performs about $1400 \mathrm{~mm} /$ year to $1600 \mathrm{~mm} /$ year with an average up to 1570 $\mathrm{mm} /$ year for the period; the water surplus estimated achieve an average of $604 \mathrm{~mm} /$ year, thus acomplishing a SAG active reserve of about $4,4 \times 10^{8} \mathrm{~m}^{3} /$ ano

Keywords - Water Balance; Guarani Aquifer System; Aquifer Recharge; Active Reserve.

\section{INTRODUÇÃO}

A água é um recurso natural que pode ser renovado constantemente pelo ciclo hidrológico, mas sua distribuição é variável no tempo e no espaço. Sua qualidade, quantidade e uso adequado são fundamentais para o desenvolvimento econômico, social e cultural da humanidade, de sorte que constitui um elemento fundamental em qualquer análise ambiental e de recursos naturais de uma região.

Com relação à exploração de recursos hídricos, merece menção a crescente utilização dos mananciais subterrâneos para suprir a demanda de água, tanto para o abastecimento público quanto para os diversos setores da economia. Este fato decorre das vantagens das águas subterrâneas em relação às águas superficiais, destacando-se sua qualidade, geralmente melhor graças à proteção natural dos aquíferos à contaminação, além do fator econômico. Porém, o aumento da demanda tem levado a situações de superexploração das águas subterrâneas, o que pode provocar efeitos geológicos, econômicos, sociais e/ou ecológicos, cujo balanço final é negativo à sociedade atual e às gerações futuras. 
Tal situação exige estudos e instrumentos legais normativos que avaliem a utilização e a potencialidade de exploração de mananciais hídricos, englobando análises de balanço hídrico e de estimativas de reservas hídricas subterrâneas, com vistas ao desenvolvimento sustentável. Assim, a determinação do balanço hídrico regional é de grande relevância em estudos que necessitem do conhecimento sobre a disponibilidade de água, sendo sua quantificação de grande utilidade para determinar estratégias de gestão dos recursos hídricos.

Dados de precipitação e temperatura fornecem subsídios para a avaliação do balanço hídrico regional e, por sua vez, para o planejamento ambiental. Dessa forma, utilizou-se desse tipo de dados para a determinação do balanço hídrico regional do Sistema Aquífero Guarani (SAG), em sua área de afloramentos no estado de São Paulo. Com isso, buscou-se compreender os ganhos e perdas recorrentes no ciclo hidrológico na região, e assim estabelecer o cálculo da recarga direta por precipitação. Os dados pluviométricos e de temperatura utilizados pertencem à série histórica de 1982 a 1995, obtidos junto ao Departamento de Água e Energia Elétrica do estado de São Paulo (DAEE).

\section{Caracterização do Sistema Aquífero Guarani (SAG)}

O SAG está localizado na porção centro-sul da América do Sul, com área de aproximadamente um milhão de quilômetros quadrados, estendendo-se pelo Brasil, Argentina, Paraguai e Uruguai. No Brasil, abrange oito estados que utilizam o sistema aquífero para suprir a demanda de água. No estado de São Paulo, ocorre entre os paralelos $20^{\circ}$ e $20^{\circ} 30^{\prime}$ de latitude $S$ e os meridianos $47^{\circ}$ e $52^{\circ} 30^{\prime}$ de longitude W, com extensão de aproximadamente 155800 $\mathrm{km}^{2}$; esse estado é o principal usuário das águas do SAG, respondendo por mais da metade dos poços cadastrados que hoje explotam esse sistema aquífero (CHANG, 2001; HIRATA et al., 2008).

Em termos geológicos, o SAG é sobreposto por rochas vulcânicas básicas em $90 \%$ do território paulista (porções central e oeste do estado), margeado a leste por uma faixa alongada aflorante, de direção aproximada NE-SW, na porção central do estado. Essa faixa ocupa área de aproximadamente $18400 \mathrm{~km}^{2}$ e constitui a principal zona de recarga desse sistema aquífero (Figura 1). O SAG é composto pelas formações Pirambóia (Triássico) e Botucatu (Jurássico Superior a Cretáceo Inferior), unidades litoestratigráficas da Bacia Sedimentar do Paraná definidas formalmente por Soares (1973, 1975). Regionalmente, o SAG está alojado entre as rochas permianas do Grupo Passa Dois e os derrames basálticos eo-cretáceos da Formação Serra Geral (região de confinamento); localmente pode ocorrer recoberto diretamente por rochas do Grupo Bauru (CHANG, 2001; HIRATA et al., 2008).

Segundo Caetano-Chang (1997), a Formação Pirambóia foi depositada em um sistema eólico com metassaturação em areias, onde se intercalam arenitos finos e muito finos de fácies de dunas com arenitos siltosos de fácies de interdunas úmidas e, subordinadamente, fácies fluviais de rios temporários; o terço superior da unidade é formado por uma associação de arenitos conglomeráticos e conglomerados de leques aluviais, com arenitos médios a grossos de dunas eólicas (Arenitos Itirapina de CAETANO-CHANG e WU, 2006). A Formação Botucatu é formada por arenitos finos a médios de fácies de dunas eólicas, em uma sucessão monótona de dunas e interdunas secas de um sistema saturado em areias.

Para Araújo et al. (1995), o arcabouço hidrogeológico do SAG teria se desenvolvido a partir do Cretáceo, quando, com o soerguimento das bordas da Bacia Sedimentar do Paraná, a erosão das sequências sedimentares sobrepostas possibilitou o afloramento de suas unidades hidroestratigráficas e, consequentemente, a recarga do sistema a partir das águas meteóricas nessas porções elevadas. 


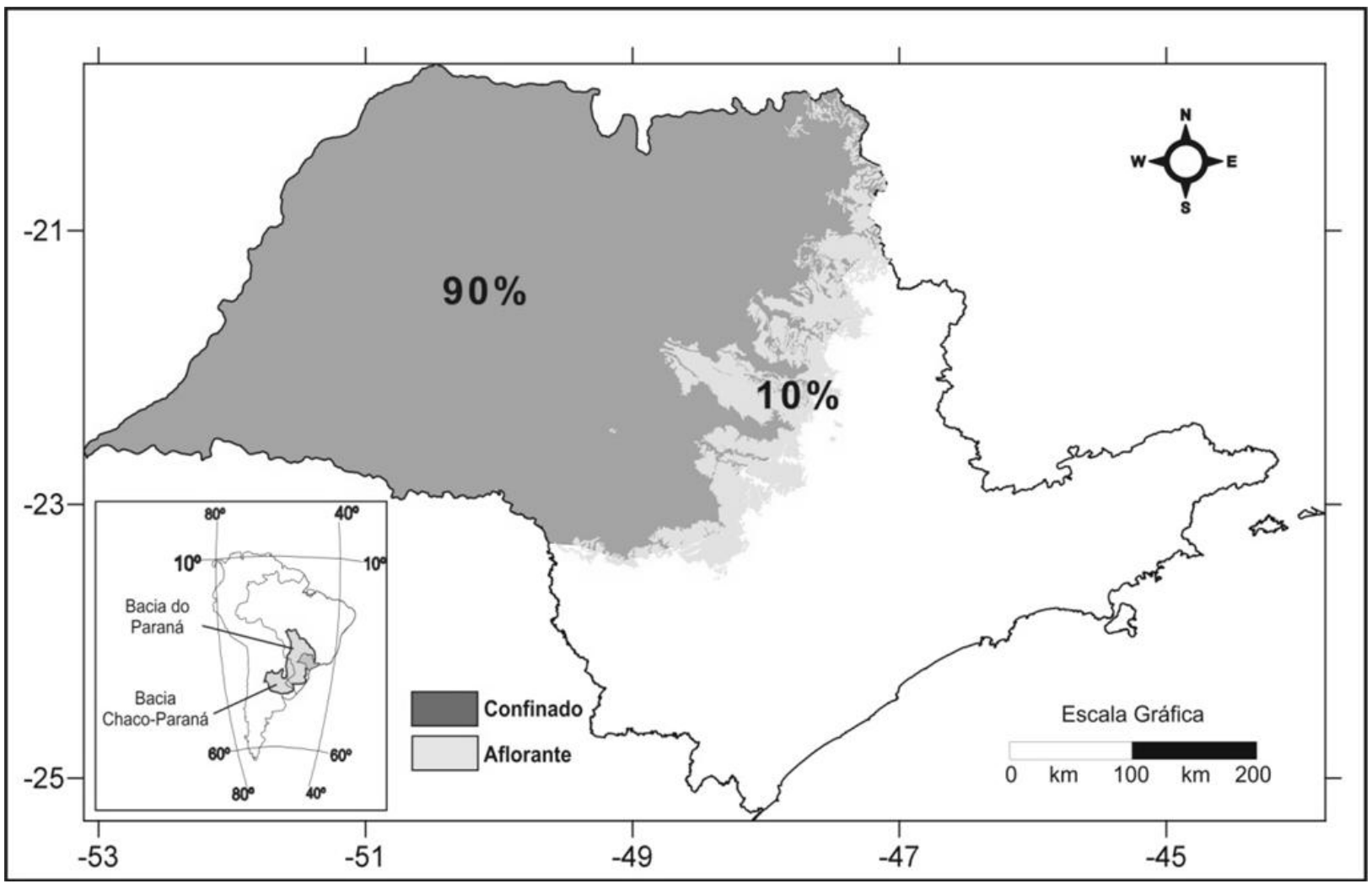

Figura 1 - Ocorrência do Sistema Aquífero Guarani no estado de São Paulo. Modificado de LEBAC (2004).

Em sua porção aflorante, próximo à borda oeste da Depressão Periférica Paulista, o SAG constitui um aquífero granular, homogêneo e regionalmente livre. É nessa faixa sudoestenordeste e em suas proximidades que se concentram os poços que exploram o sistema aquífero. Contudo, mesmo em sua zona de maior confinamento, onde os custos de perfuração e manutenção dos poços são elevados, importantes cidades utilizam o SAG para abastecimento de água, como São José do Rio Preto, Presidente Prudente, Marília e Araçatuba. O SAG recebe recarga a partir de dois mecanismos principais: por infiltração direta de parte das precipitações que ocorrem em sua zona de afloramentos, indo formar as reservas ativas; e indiretamente das formações sobrepostas - Formação Serra Geral (através de sistemas de fraturas nessas rochas) e Grupo Bauru (através dos poros desses arenitos).

A primeira avaliação de reservas na porção brasileira do SAG deve-se a Rebouças (1976). Na ocasião, a reserva permanente foi estimada em $48021 \mathrm{~km}^{3}$ e a reserva reguladora ou ativa em $160 \mathrm{~km}^{3} /$ ano, subdivididas em infiltração direta e indireta. A infiltração direta foi calculada considerando-se uma recarga equivalente a $15 \%$ da pluviometria média anual de $1500 \mathrm{~mm}$, precipitando sobre uma área de $87000 \mathrm{~km}^{2}$. A infiltração indireta foi calculada adotando-se valores de condutividade hidráulica, valor médio de $5.10^{-8} \mathrm{~m} / \mathrm{s}$ e de diferença de potencial e espessura média de camada porosa, entre $100 \mathrm{~m}$ e $400 \mathrm{~m}$, respectivamente. Para a estimativa da reserva permanente, foi utilizada uma área total de $800000 \mathrm{~km}^{2}$, espessura média de 300 m e porosidade efetiva de $20 \%$.

Rocha (1997) apresentou uma avaliação para toda a área do SAG no Brasil, fornecendo valores de $37000 \mathrm{~km}^{3}$ e $160 \mathrm{~km}^{3} /$ ano para as reservas permanente e ativa, respectivamente. Os parâmetros utilizados foram: pluviometria média de $1500 \mathrm{~mm} / \mathrm{ano}$, área de recarga de 150 $000 \mathrm{~km}^{2}$, área confinada de um milhão $\mathrm{km}^{2}$, espessura média de $250 \mathrm{~m}$, porosidade eficaz de $15 \%$ e coeficiente de armazenamento de $10^{-4}$. Nesse trabalho o autor adotou, também, o valor de $25 \%$ como índice de reserva explorável, justificando a necessidade de planejamento racional do uso e reduzindo sobremaneira o volume correspondente à reserva ativa. 
Estudos no município de Ribeirão Preto, localizado na zona de afloramentos do SAG no estado de São Paulo, mostraram que as taxas de recarga são da ordem de $4 \%$ do índice pluviométrico (SINELLI, 1987; FIPAI, 1996), bem abaixo dos valores utilizados nos cálculos de recarga por diversos autores, que são da ordem de $15 \%$. Chang (2001) utilizou-se dessa taxa de recarga mais conservadora e calculou a reserva ativa para o SAG, em território brasileiro, baseando-se em um índice pluviométrico médio de $1300 \mathrm{~mm}$ a $1500 \mathrm{~mm}$ e área de afloramento com 89936 $\mathrm{km}^{2}$; o valor obtido foi de aproximadamente $5,2 \mathrm{~km}^{3} / \mathrm{ano}$.

\section{Clima na área de estudo}

As reservas subterrâneas de aquíferos livres estão diretamente ligadas às condições climáticas, podendo variar de acordo com a distribuição da precipitação e com as temperaturas médias da região.

Rolim et al. (2007) atualizaram o mapeamento das classificações climáticas pelo sistema Köppen (SETZER, 1966) para o Estado de São Paulo. Essa atualização foi motivada, principalmente, pelo maior número de estações agrometeorológicas implantadas no estado e pela avaliação das potenciais aplicações em estudos de zoneamentos agroclimáticos. De acordo com os mesmos autores, a densidade de pontos espaciais proporcionou boa acurácia na determinação dos tipos climáticos.

De acordo esse estudo, o tipo climático dominante das áreas de afloramento do SAG no estado de São Paulo se situa na transição entre os climas Cfa, Aw, Cwa, e localmente, o Cwb e AM. O tipo dominante, com maior área de influência na região em estudo, é o Cfa, com verão quente e sem estação seca de inverno, em que a temperatura média do mês mais frio está entre 18 ${ }^{\circ} \mathrm{C}$ e $-3{ }^{\circ} \mathrm{C}$, que abrange toda a parte central do estado de São Paulo. Já as porções norte e noroeste da área de estudo, mais quentes, pertencem ao tipo Aw e localmente Am, climas tropicais chuvosos com inverno seco e mês mais frio com temperatura média superior a $18^{\circ} \mathrm{C}$. $\mathrm{Na}$ porção sudeste da área de estudo aparecem faixas de clima tropical, do tipo Cwa que apresenta como característica fundamental o clima tropical de altitude, com chuvas no verão e seca no inverno, com a temperatura média do mês mais quente superior a $22^{\circ} \mathrm{C}$. Este tipo climático caracteristicamente possui verão quente e inverno não muito frio, tipicamente subtropical. O mês mais seco tem precipitação inferior a $60 \mathrm{~mm}$ e o período chuvoso avança na estação de outono. Algumas áreas serranas, com verão ameno, são classificadas como $\mathrm{Cwb}$, em que a temperatura média do mês mais quente é inferior a $22^{\circ} \mathrm{C}$ e, durante pelo menos quatro meses, é superior a $10{ }^{\circ} \mathrm{C}$. Com relação à precipitação, as chuvas são naturalmente abundantes para todo o estado de São Paulo, com índices anuais médios para a área de estudo entre $1100 \mathrm{~mm}$ e $2000 \mathrm{~mm}$.

A Figura 2 apresenta o Sistema Internacional de Classificação Climática de Köeppen, baseado no total de precipitação (ROLIM et al., 2007). 


\begin{tabular}{|c|c|c|c|c|c|c|c|}
\hline \multicolumn{2}{|c|}{ 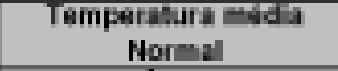 } & \multirow{2}{*}{$\begin{array}{l}\text { Tolal de } \\
\text { chowa do } \\
\text { moss mals } \\
\text { sooo (Pes] }\end{array}$} & \multirow{2}{*}{$\begin{array}{c}\text { Toial de chuva anual } \\
\text { (P) }\end{array}$} & \multirow{2}{*}{\multicolumn{3}{|c|}{$\begin{array}{l}\text { Descriçaso do Tipo de Clima } \\
\text { segundo Koppen } \\
\text { (Climas Umides) }\end{array}$}} & \multirow{2}{*}{ Simbole } \\
\hline $\begin{array}{l}\text { do mós } \\
\text { mais trio }\end{array}$ & $\begin{array}{c}\text { do mas mis } \\
\text { quons }\end{array}$ & & & & & & \\
\hline \multirow{3}{*}{$p=18 \mathrm{C}$} & \multirow{4}{*}{$2=2200$} & $s=60 \mathrm{~mm}$ & & \multirow{2}{*}{\multicolumn{2}{|c|}{ TROPICAL }} & $\begin{array}{c}\text { sem estopión } \\
\text { seca }\end{array}$ & Af \\
\hline & & \multirow{2}{*}{ c 60mm } & $\therefore \quad 800-772 T$ P Pms & & & \multirow{4}{*}{$\begin{array}{c}\text { Inverno } \\
\text { Seco }\end{array}$} & Aw \\
\hline & & & $p=200-27,27$. Pms & $\begin{array}{r}\text { Th } \\
\text { che }\end{array}$ & $\begin{array}{l}\text { POFICAL com } \\
\text { Jvas excesdivas }\end{array}$ & & $\mathrm{Am}$ \\
\hline \multirow{4}{*}{$<180 \mathrm{C}$} & & \multirow{2}{*}{$<30 \mathrm{~mm}$} & & \multirow{4}{*}{ 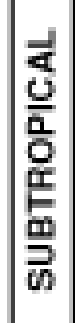 } & Quente & & Cwa \\
\hline & $<220 \mathrm{C}$ & & & & Temperado & & Cwb \\
\hline & $>=22 \times 0$ & \multirow{2}{*}{$s=30 \mathrm{~mm}$} & & & Quente & \multirow{2}{*}{$\begin{array}{l}\text { sem } \\
\text { estaçâo } \\
\text { raca }\end{array}$} & Cfa \\
\hline & $\therefore 2200$ & & & & Temperado & & $\mathrm{Cfb}$ \\
\hline
\end{tabular}

Figura 2 - Chave para Classificação Climática de Köeppen. Fonte: Rolim et al, 2007.

\section{MATERIAIS E MÉTODOS}

O mapeamento das áreas de afloramento do SAG baseou-se em Perrota et al. (2005), DAEE/IG/IPT/CPRM (2005), e em Hirata et al., 2008. Os dados referentes aos volumes de precipitação e médias de temperatura foram obtidos em estações meteorológicas pertencentes ao DAEE e localizadas na área de interesse.

O balanço hídrico fornece estimativas da evapotranspiração potencial e relativa, da deficiência e do excedente hídrico e do armazenamento de água no solo. Constitui, assim, um indicador climatológico fundamental para o cálculo da disponibilidade hídrica em uma região, o que é fundamental para o planejamento ambiental e para o uso sustentável dos recursos hídricos (Graham et al., 2004).

A determinação do balanço hídrico climatológico pelo método de Thornthwaite e Matter (1955) é uma das várias maneiras de se monitorar a variação da disponibilidade hídrica para a recarga de aquíferos e leva em consideração o suprimento natural de água para o solo, a demanda atmosférica e a quantidade de água disponível para a recarga de aquíferos. Esse método permite uma melhor compreensão dos ganhos e perdas constantes no ciclo hidrológico, uma vez que as chuvas influenciam diretamente o volume de infiltração e, por conseguinte, a recarga direta do sistema aquífero.

A disponibilidade hídrica em forma de excedentes é o resultado do confronto entre os valores de evapotranspiração e precipitação pluviométrica, ou seja, aquele montante que não foi evapotranspirado é que irá abastecer as águas subterrâneas, os rios, o utilizável pelas plantas. Desse modo, para o cálculo dos excedentes e deficiências hídricas na área de afloramentos do SAG, com base no método de Thornthwaite e Mather (1955), foi utilizado o modelo computacional baseado no software Bhhorm v5, elaborado pelo departamento de Física e Meteorologia da ESALQ/USP (ROLIM, et al., 1998) com base em planilhas do Microsoft Excel.

Estima-se que, durante o processo de recarga, a parcela de precipitação que atinge o nível potenciométrico do SAG em sua porção livre, sob a forma de taxa de infiltração, é da ordem de $20 \%$ da precipitação total (VELÁSQUEZ, 1996); (SINELLI et al., 2008). Parte dessa recarga retorna à superfície na forma de escoamento básico, assegurando a perenidade dos rios, mesmo nos períodos de estiagem, e apenas uma fração da recarga direta permanece no meio subterrâneo e contribui para a recarga profunda do SAG, formando a reserva ativa ou 
renovável do aquífero, disponível para captação e distribuição para consumo para os mais diversos tipos de usos.

Diversos autores (SINELLI, 1984; FIPAI, 1996; CHANG, 2001) consideram que essa parcela renovável corresponde a $4 \%$ da precipitação total; Sinelli et al. (2008) consideraram uma margem um pouco superior, como $5 \%$ da pluviometria total anual para esse cálculo. 0 cálculo da reserva ativa no presente estudo utilizou o montante de $4 \%$ do excedente hídrico médio, referente ao balanço hídrico no período de 1982 a 1995, para o cálculo da reserva renovável na área de estudo.

Assim, o cálculo da reserva ativa ou renovável se resume à seguinte equação:

$$
R_{a}=\frac{E X C \times 4}{100} \times \mathrm{A}
$$

Onde Ra é a reserva ativa ou renovável, EXC é o excedente hídrico médio para as áreas de recarga do SAG menos o resultado do balanço hídrico, e A é a área de estudo em $\mathrm{km}^{2}$.

O balanço hídrico do SAG, na área de estudo, foi determinado com base em dados pluviométricos e de temperatura pertencentes à série histórica de 1982 a 1995, obtidos junto ao DAEE. Dadas a disponibilidade da informação e a consistência dos dados, cinco estações meteorológicas foram selecionadas: Nuporanga (código DAEE B4-066M), Santa Rita do Passa Quatro (C4-107M), Analândia (D4-108M), Botucatu (D5-059M) e Piraju (código DAEE E6$006 \mathrm{M})$, todas na zona de afloramento do SAG ou próximas a esta (Figura 3).

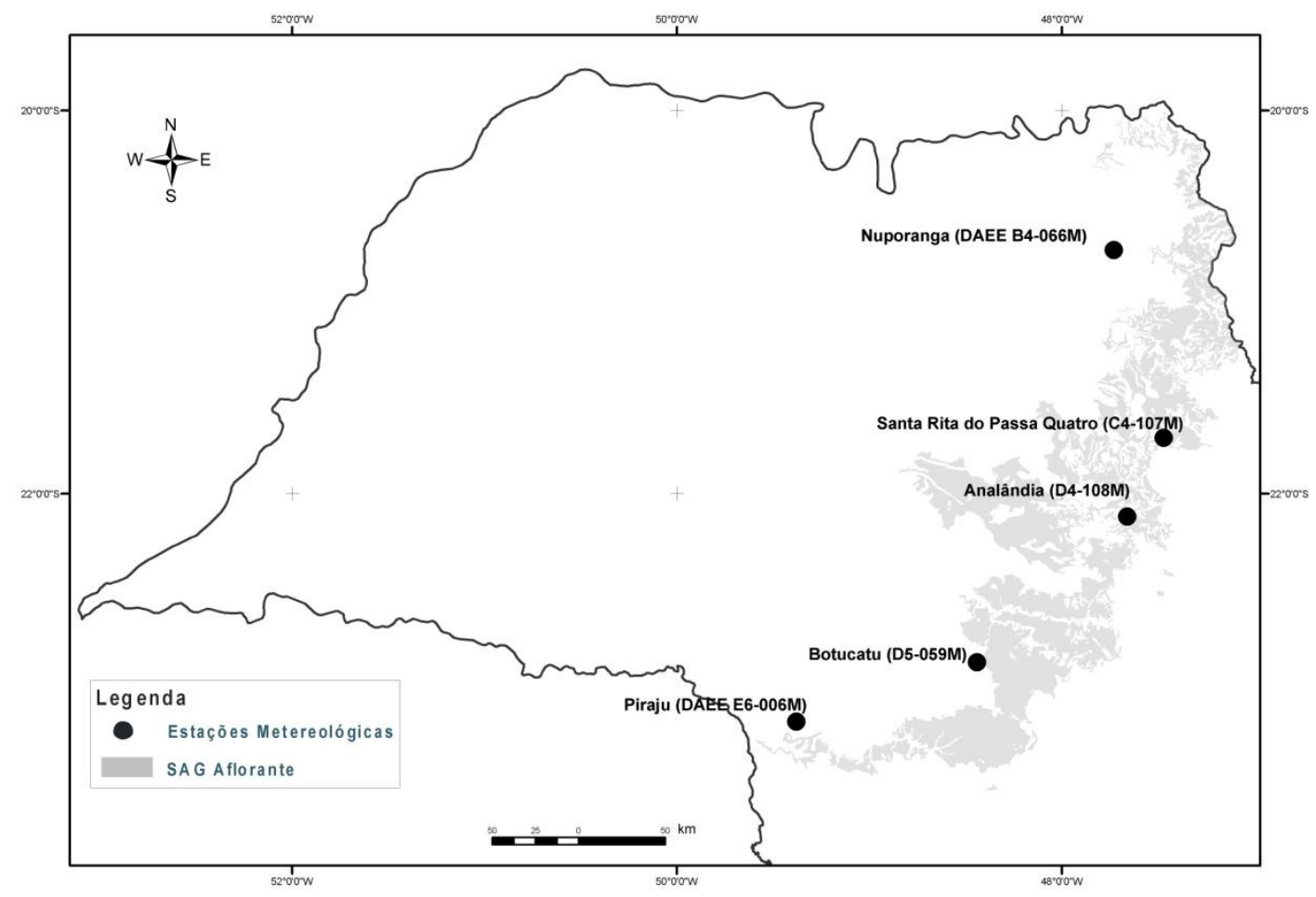

Figura 3 - Mapa de localização das estações meteorológicas selecionadas 


\section{DISCUSSÃO DOS RESULTADOS}

As estações localizadas na porção norte da área de afloramentos do SAG (Nuporanga e Santa Rita do Passa Quatro) apresentaram as maiores médias mensais de temperatura do ar $(21,4$ ${ }^{\circ} \mathrm{C}$ e $21,6{ }^{\circ} \mathrm{C}$, respectivamente), os maiores picos de precipitação $(305,7 \mathrm{~mm}$ e $258,4 \mathrm{~mm}$, respectivamente) e o menor gradiente térmico (de acordo com a variação da curva de temperatura do ar) (Figuras 4 e 5); também mostraram os menores índices pluviométricos nos períodos de estiagem, de julho a agosto.

Conforme pode ser observado nas figuras 4 e 5, as estações da porção norte da área de estudo apresentaram temperaturas máximas do ar médias para os meses mais quentes acima de $22{ }^{\circ} \mathrm{C}$, médias menores que $30 \mathrm{~mm}$ de chuva nos meses mais secos e temperaturas médias mínimas acima de $18^{\circ} \mathrm{C}$.

\section{Nuporanga}

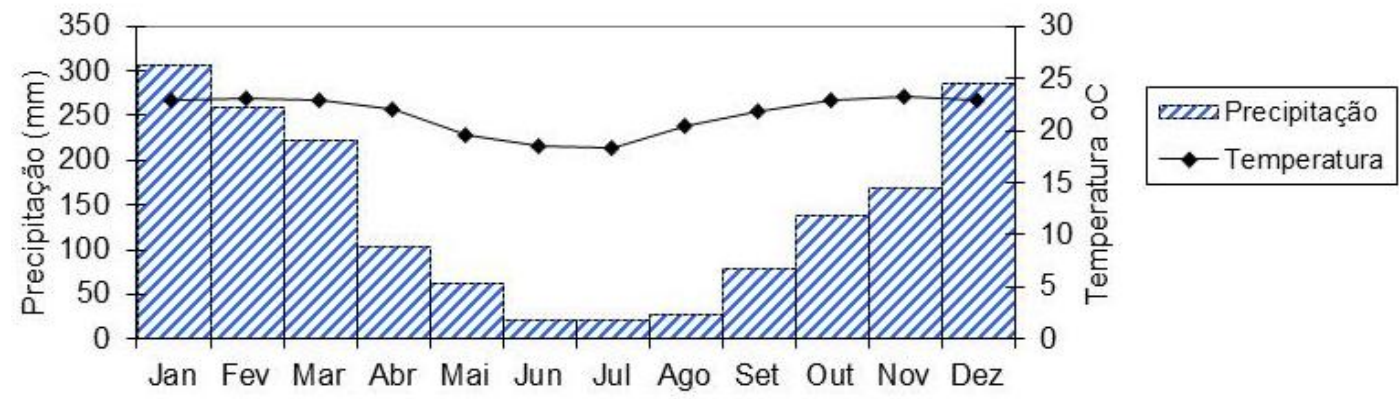

Figura 4 - Média de distribuição mensal pluviométrica e de temperatura do ar para a estação meteorológica de Nuporanga, entre 1982 e 1995.

\section{Santa Rita do Passa Quatro}

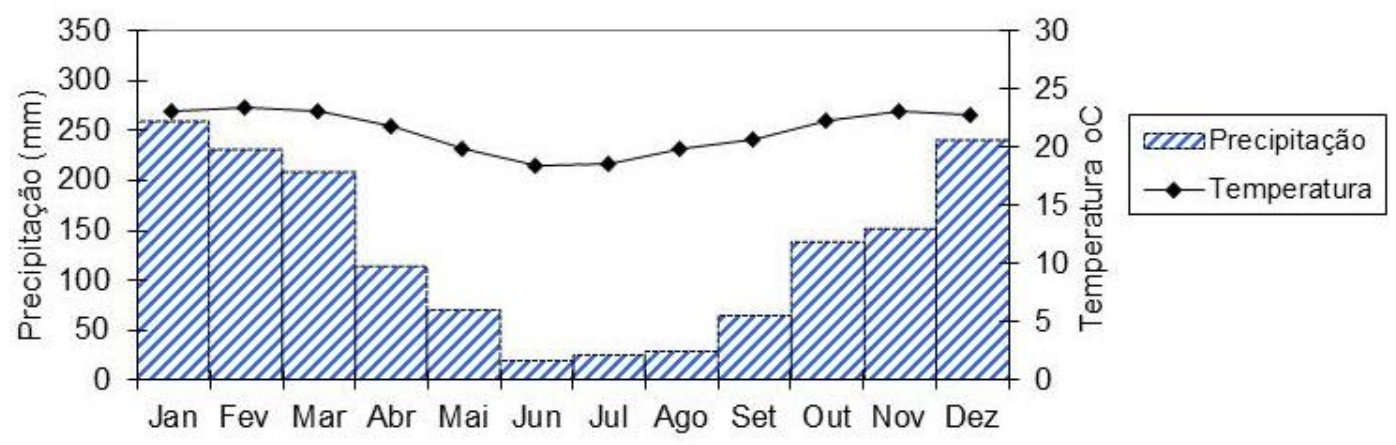

Figura 5 - Média de distribuição mensal pluviométrica e de temperatura do ar para a estação meteorológica de Santa Rita do Passa Quatro, entre 1982 e 1995.

As estações da porção sul da área de estudo (Botucatu e Piraju) apresentaram, para o período amostrado, temperaturas máximas do ar médias para os meses mais quentes acima de $22{ }^{\circ} \mathrm{C}$, médias superiores a $30 \mathrm{~mm}$ de chuva nos meses mais secos e temperaturas médias mínimas do ar menores que $18{ }^{\circ} \mathrm{C}$ (Figuras 6 e 7), caracterizando o tipo climático Cfa. Para a estação no centro da área (Analândia), os dados levantados mostram que o tipo climático é também 
Cfa, mas próximo ao clima Cwa, pois apresentou 30,1 mm de chuva no mês mais seco (Figura 8).

\section{Botucatu}

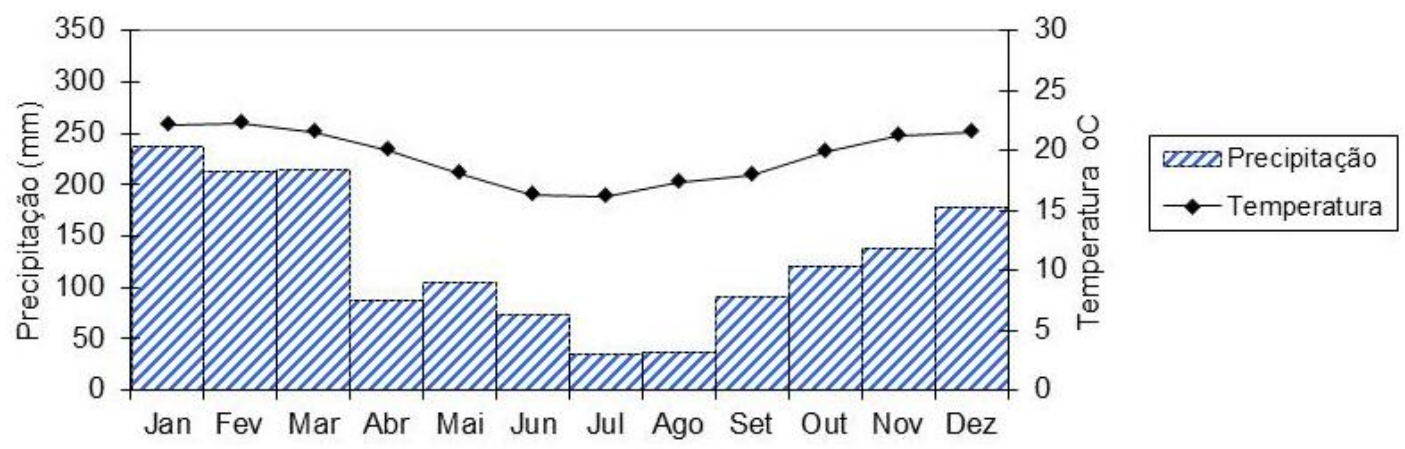

Figura 6 - Média de distribuição mensal pluviométrica e de temperatura do ar para a estação meteorológica de Botucatu, entre 1982 e 1995.

\section{Piraju}

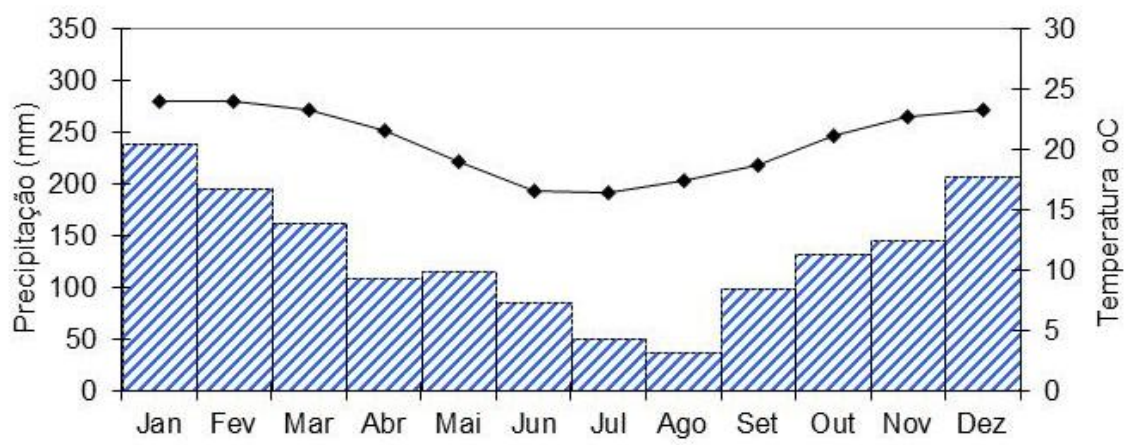

zZzֵs Precipitação

$\multimap$ Temperatura

Figura 7 - Média de distribuição mensal pluviométrica e de temperatura para a estação meteorológica de Piraju, entre 1982 e 1995.

\section{Analândia}

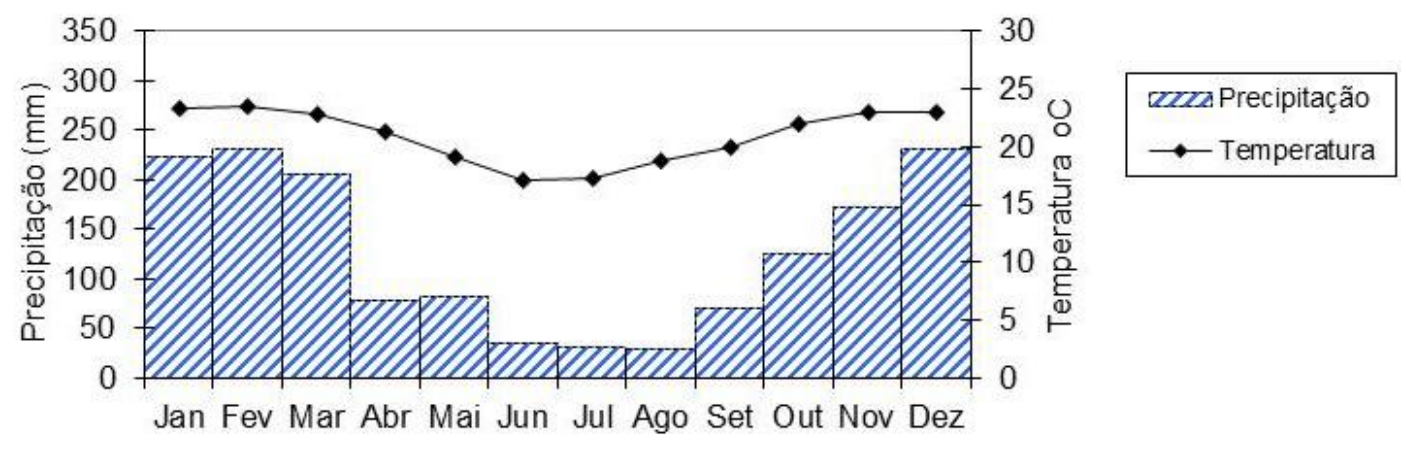

Figura 8 - Média de distribuição mensal pluviométrica e de temperatura do ar para a estação meteorológica de Analândia, entre 1982 e 1995. 
De maneira geral, embora na área de estudo não existam dados disponíveis sequenciais de no mínimo 30 anos, com base na classificação climática de Köeppen (Figura 2), os resultados apresentados para as médias mensais de precipitação e temperatura, são concordantes com os tipos climáticos estabelecidos para a área de estudo.

Entre os anos de 1982 e 1995, a distribuição sazonal das chuvas e a oscilação das temperaturas médias, nas estações meteorológicas pesquisadas, mostrou resultados típicos de clima tropical quente, condizente com as latitudes médias da área de estudo. A partir dos dados de precipitação constatou-se que as taxas pluviométricas na área de afloramento das formações geológicas constituintes do SAG são da ordem de 1400 mm/ano a 1600 mm/ano, com média para o período levantado de $1570 \mathrm{~mm} / \mathrm{ano}$.

A definição da classificação climática é de grande importância, pois permitiu considerar para o trabalho, mesmo através da utilização de dados não muito recentes, reproduzir as mesmas condições climáticas para os dias atuais, não interferindo, dessa forma, nos mecanismos e disponibilidade hídrica para a recarga de aquíferos.

Cabe observar que a presente análise não considera o debate sobre as mudanças climáticas globais, ligadas sobretudo ao aquecimento atmosférico e à variabilidade na distribuição das chuvas de determinadas localidades que, por consequência, podem vir a interferir nas taxas de recarga dos principais sistemas aquíferos.

Os levantamentos de temperatura do $\operatorname{ar}(T)$ e pluviosidade $(P)$ nas estações meteorológicas foram utilizados na determinação do balanço hídrico regional, por meio do método de Thornthwaite e Mather (1955), o que propiciou a determinação da evapotranspiração potencial e dos excedentes e deficiências hídricas. As tabelas de 1 a 5 mostram esses levantamentos apresentado através do cálculo das médias anuais para o período amostrado, que por sua vez, foram utilizados para as determinações evapotranspiração potencial (ETP), evapotranspiração real (ETR), armazenamento mensal (ARM), deficiências hídricas (DEF) e excedentes hídricos (EXC). As figuras de 9 a 18 mostram o balanço hídrico nas estações meteorológicas na área de afloramentos do SAG.

A estação de Nuporanga apresenta os maiores índices pluviométricos, com excedente hídrico total médio de $700 \mathrm{~mm}$ (Tabela 1), porém, Nuporanga apresenta cinco meses de deficiência hídrica e três meses de retirada (Figuras 9 e 10). A reposição hídrica das retiradas deveu-se à precipitação média ocorrida nos meses de outubro e parcialmente nos meses de novembro (Figura 10). Os meses de retirada e de deficiência hídrica ocorreram devido aos altos índices de evapotranspiração e à distribuição irregular das chuvas ao longo dos anos de 1982 e 1995, principalmente nos meses mais secos.

A estação de Santa Rita do Passa Quatro apresenta excedente hídrico total médio de 571,8 $\mathrm{mm}$ (Tabela 2), com quatro meses de deficiência hídrica (Figuras 11 e 12). Para a reposição hídrica dos meses em que ocorreram as retiradas foram necessárias chuvas fortes e bem distribuídas no período de apenas 1,5 mês (outubro e novembro) (Figura 12). Os meses de retirada e de deficiência hídrica podem ser explicados pelas mesmas causas aventadas para a estação de Nuporanga (Figuras 9 e 10), apesar de pequenas diferenças no balanço hídrico local. 
Tabela 1

Temperatura do ar e pluviometria média mensal e extrato do balanço hídrico médio mensal, entre 1982 e 1995, na estação meteorológica de Nuporanga.

\begin{tabular}{cccccccc}
\hline Meses & $\begin{array}{c}\text { oC } \\
\text { Jan }\end{array}$ & $\begin{array}{c}\mathbf{P} \\
\mathbf{m m}\end{array}$ & $\begin{array}{c}\text { ETP } \\
\text { Thornthwaite } \\
\mathbf{1 9 8 2 - 1 9 9 5}\end{array}$ & $\begin{array}{c}\text { ARM } \\
\mathbf{m m}\end{array}$ & $\begin{array}{c}\text { ETR } \\
\mathbf{m m}\end{array}$ & $\begin{array}{c}\text { DEF } \\
\mathbf{m m}\end{array}$ & $\begin{array}{c}\text { EXC } \\
\mathbf{m m}\end{array}$ \\
\hline Fev & 23,1 & 305,7 & 108,69 & 100,00 & 108,7 & 0,0 & 197,1 \\
Mar & 23,0 & 259,1 & 98,60 & 100,00 & 98,6 & 0,0 & 160,5 \\
Abr & 22,1 & 101,8 & 103,39 & 100,00 & 103,4 & 0,0 & 119,0 \\
Mai & 19,6 & 61,3 & 86,10 & 100,00 & 86,1 & 0,0 & 15,7 \\
Jun & 18,6 & 20,3 & 51,67 & 97,89 & 63,4 & 0,0 & 0,0 \\
Jul & 18,3 & 20,5 & 51,01 & 71,55 & 46,7 & 5,0 & 0,0 \\
Ago & 20,4 & 27,4 & 68,81 & 52,71 & 39,3 & 11,7 & 0,0 \\
Set & 21,8 & 78,4 & 81,63 & 33,83 & 45,3 & 23,6 & 0,0 \\
Out & 23,0 & 136,8 & 101,27 & 69,26 & 101,3 & 0,0 & 0,0 \\
Nov & 23,3 & 167,7 & 105,70 & 100,00 & 105,7 & 0,0 & 31,3 \\
Dez & 22,9 & 284,4 & 107,84 & 100,00 & 107,8 & 0,0 & 176,6 \\
\hline TOTAIS & 258,9 & 1685,9 & 1028,18 & 960 & 985,8 & 42,4 & 700,1 \\
\hline MÉDIAS & 21,6 & 140,5 & 85,68 & 80,0 & 82,1 & 3,5 & 58,3 \\
\hline
\end{tabular}
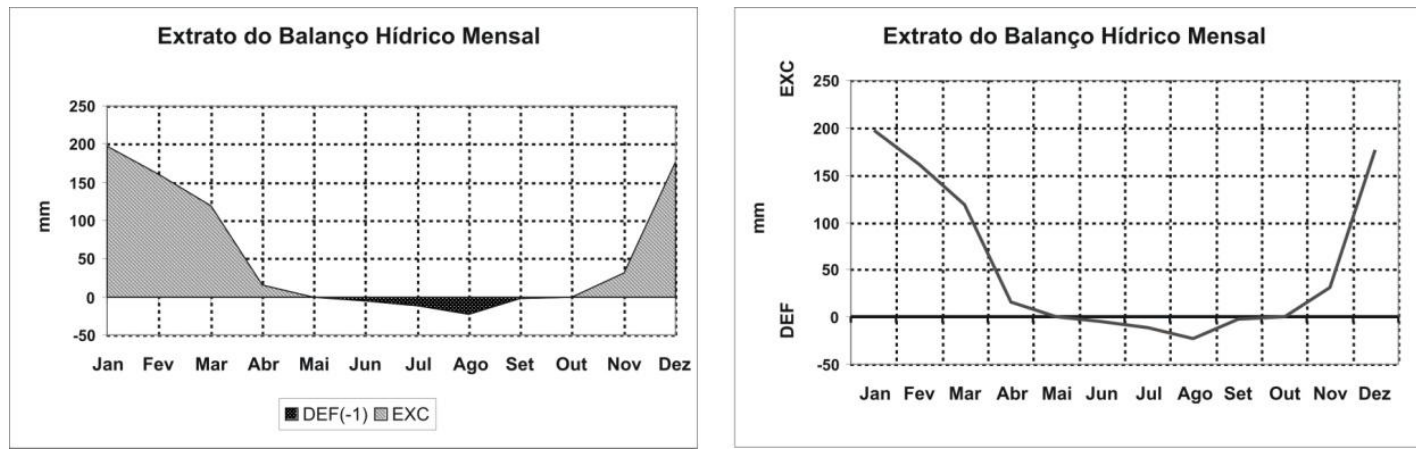

Figura 9 - Extrato do balanço hídrico médio mensal, entre 1982 e 1995, na estação meteorológica de Nuporanga.
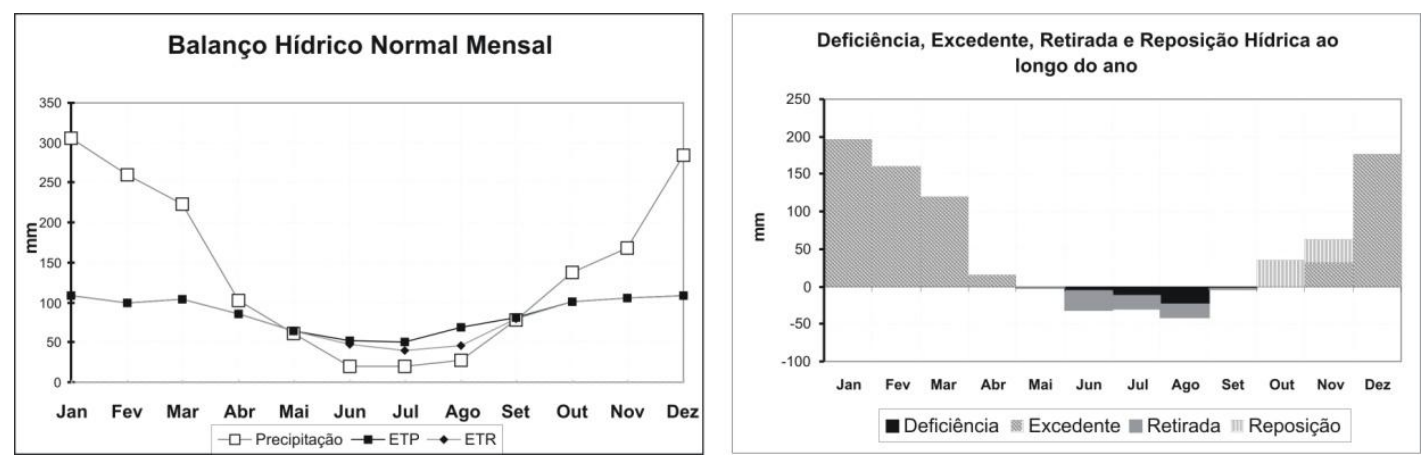

Figura 10 - Distribuição da precipitação e dos valores médios mensais de temperatura do ar e evapotranspiração (esquerda) e média mensal de deficiência, excedente, retirada e reposição hídrica (direita), entre 1982 e 1995, na estação meteorológica de Nuporanga. 
Tabela 2

Temperatura do ar e pluviometria média mensal e extrato do balanço hídrico médio mensal, entre 1982 e 1995, na estação meteorológica de Santa Rita do Passa Quatro.

\begin{tabular}{cccccccc}
\hline Meses & $\mathbf{T}$ & $\mathbf{m m}$ & $\begin{array}{c}\text { ETP } \\
\text { Thornthwaite } \\
\mathbf{1 9 8 2 - 1 9 9 5}\end{array}$ & $\begin{array}{c}\text { ARM } \\
\mathbf{m m}\end{array}$ & $\begin{array}{c}\text { ETR } \\
\mathbf{m m}\end{array}$ & $\begin{array}{c}\text { DEF } \\
\mathbf{m m}\end{array}$ & $\begin{array}{c}\text { EXC } \\
\mathbf{m m}\end{array}$ \\
\hline Jan & 23,1 & 258,4 & 112,51 & 100,00 & 112,5 & 0,0 & 145,9 \\
Fev & 23,5 & 230,2 & 102,91 & 100,00 & 102,9 & 0,0 & 127,3 \\
Mar & 23,0 & 208,4 & 104,24 & 100,00 & 104,2 & 0,0 & 104,1 \\
Abr & 21,8 & 113,5 & 84,24 & 100,00 & 84,2 & 0,0 & 29,2 \\
Mai & 19,9 & 71,5 & 65,66 & 100,00 & 65,7 & 0,0 & 5,9 \\
Jun & 18,5 & 20,4 & 51,26 & 73,42 & 46,9 & 4,3 & 0,0 \\
Jul & 18,5 & 25,3 & 53,10 & 55,60 & 43,1 & 10,0 & 0,0 \\
Ago & 19,9 & 30,3 & 64,83 & 39,35 & 46,5 & 18,3 & 0,0 \\
Set & 20,7 & 65,4 & 72,25 & 36,73 & 68,0 & 4,3 & 0,0 \\
Out & 22,3 & 138,4 & 94,34 & 80,80 & 94,3 & 0,0 & 0,0 \\
Nov & 23,0 & 151,1 & 103,87 & 100,00 & 103,9 & 0,0 & 28,0 \\
Dez & 22,8 & 239,4 & 108,00 & 100,00 & 108,0 & 0,0 & 131,4 \\
\hline TOTAIS & 257,1 & 1552,2 & 1017,22 & 986 & 980,3 & 36,9 & 571,8 \\
\hline MÉDIAS & 21,4 & 129,3 & 84,77 & 82,2 & 81,7 & 3,1 & 47,7 \\
\hline
\end{tabular}
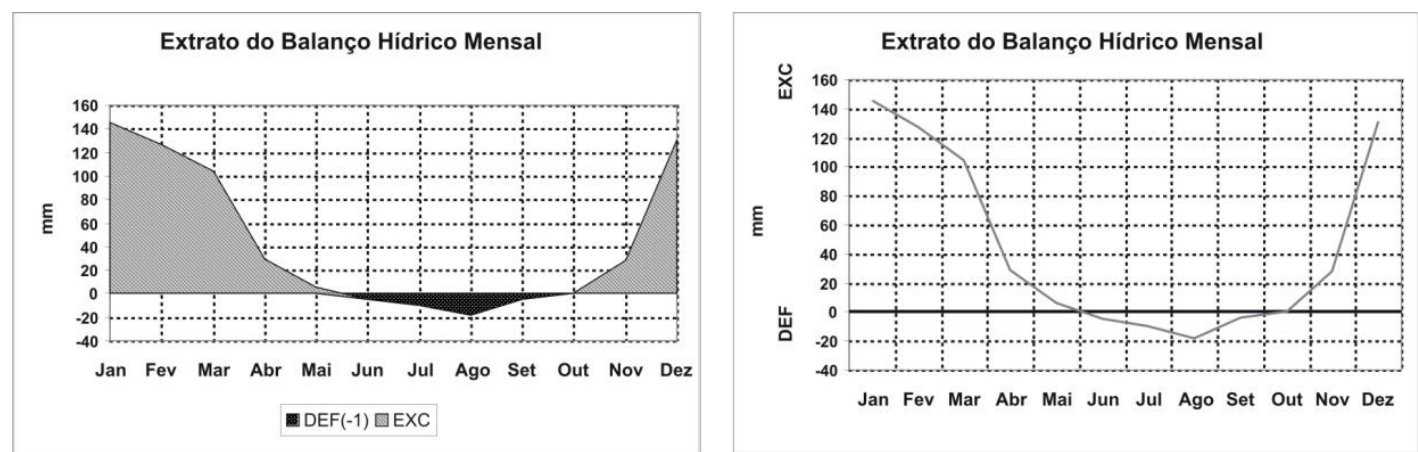

Figura 11 - Extrato do balanço hídrico médio mensal, entre 1982 e 1995, na estação meteorológica de Santa Rita do Passa Quatro.
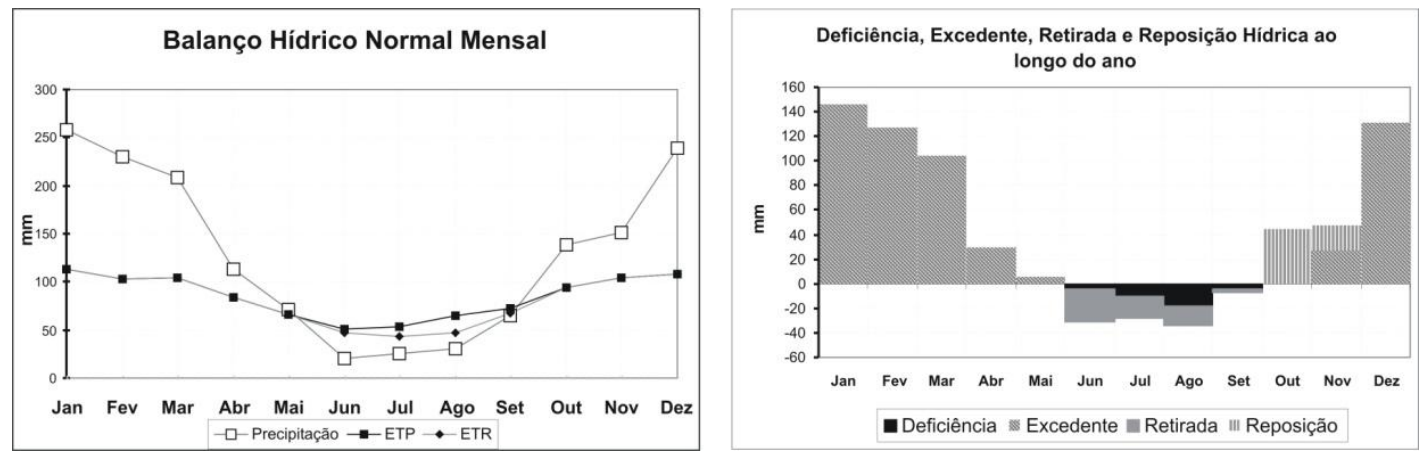

Figura 12 - Distribuição da precipitação e dos valores médios mensais de temperatura do ar e evapotranspiração (esquerda) e média mensal de deficiência, excedente, retirada e reposição hídrica (direita), entre 1982 e 1995, na estação meteorológica de Santa Rita do Passa Quatro. 
A estação meteorológica de Analândia apresenta excedente hídrico total médio de $537,7 \mathrm{~mm}$ para o período estudado (1982 a 1995) (Tabela 3), além disso, as figuras 13 e 14 mostram, de acordo com o balanço hídrico para o mesmo período, que ocorrem três meses de deficiência hídrica, mas apenas nos meses de junho, julho e agosto é detectada retirada hídrica do sistema. As reposições ocorrem em pequenas parcelas de precipitação nos meses de maio (referente ao déficit de abril) e novembro e na totalidade de setembro e outubro (referente ao déficit de junho, julho e agosto).

Tabela 3

Temperatura do ar e pluviometria média mensal e extrato do balanço hídrico médio mensal, entre 1982 e 1995, na estação meteorológica de Analândia.

\begin{tabular}{cccccccc}
\hline Meses & $\mathbf{~ O C}$ & $\begin{array}{c}\mathbf{P} \\
\mathbf{m m}\end{array}$ & $\begin{array}{c}\text { ETP } \\
\text { Thornthwaite } \\
\mathbf{1 9 8 2 - 1 9 9 5}\end{array}$ & $\begin{array}{c}\text { ARM } \\
\mathbf{m m}\end{array}$ & $\begin{array}{c}\text { ETR } \\
\mathbf{m m}\end{array}$ & $\begin{array}{c}\text { DEF } \\
\mathbf{m m}\end{array}$ & $\begin{array}{c}\text { EXC } \\
\mathbf{m m}\end{array}$ \\
\hline Jan & 23,4 & 223,4 & 117,04 & 100,00 & 117,0 & 0,0 & 106,3 \\
Fev & 23,5 & 232,0 & 104,50 & 100,00 & 104,5 & 0,0 & 127,5 \\
Mar & 22,8 & 205,2 & 103,05 & 100,00 & 103,1 & 0,0 & 102,1 \\
Abr & 21,3 & 78,2 & 81,06 & 97,14 & 81,0 & 0,0 & 0,0 \\
Mai & 19,1 & 81,8 & 61,01 & 100,00 & 61,0 & 0,0 & 17,9 \\
Jun & 17,2 & 35,2 & 44,60 & 91,02 & 44,2 & 0,4 & 0,0 \\
Jul & 17,4 & 31,4 & 46,86 & 77,98 & 44,4 & 2,4 & 0,0 \\
Ago & 18,7 & 30,1 & 57,39 & 59,37 & 48,7 & 8,7 & 0,0 \\
Set & 19,9 & 71,3 & 67,75 & 62,96 & 67,8 & 0,0 & 0,0 \\
Out & 21,9 & 126,3 & 92,16 & 97,14 & 92,2 & 0,0 & 0,0 \\
Nov & 22,9 & 172,1 & 104,17 & 100,00 & 104,2 & 0,0 & 65,0 \\
Dez & 23,0 & 230,6 & 111,74 & 100,00 & 111,7 & 0,0 & 118,9 \\
\hline TOTAIS & 251,2 & 1517,5 & 991,32 & 1086 & 979,8 & 11,6 & 537,7 \\
\hline MÉDIAS & 20,9 & 126,5 & 82,61 & 90,5 & 81,6 & 1,0 & 44,8 \\
\hline
\end{tabular}
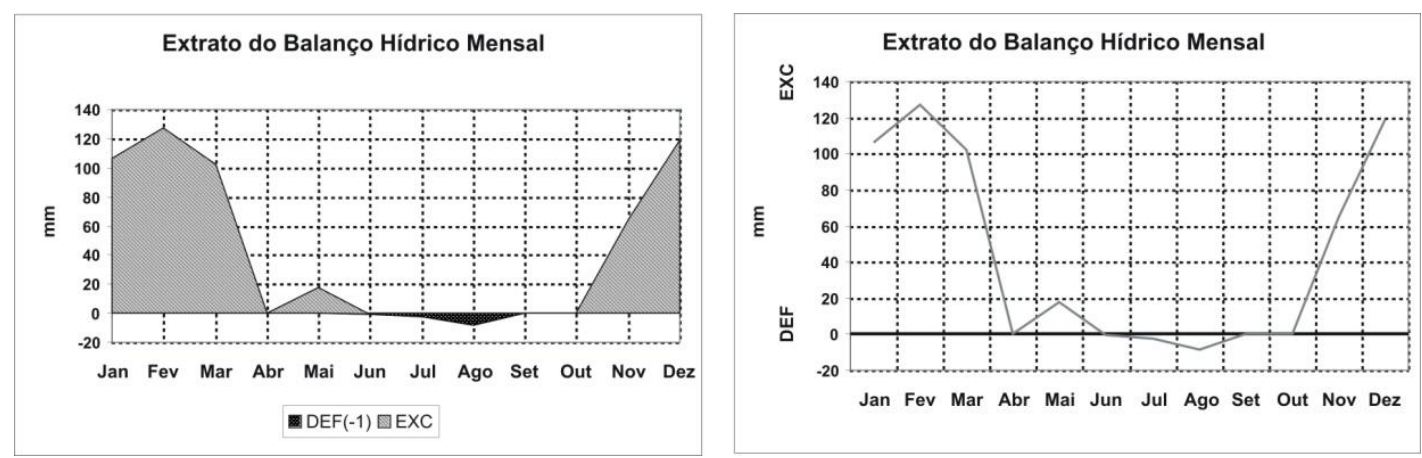

Figura 13 - Extrato do balanço hídrico médio mensal entre 1982 e 1995 na estação meteorológica de Analândia. 

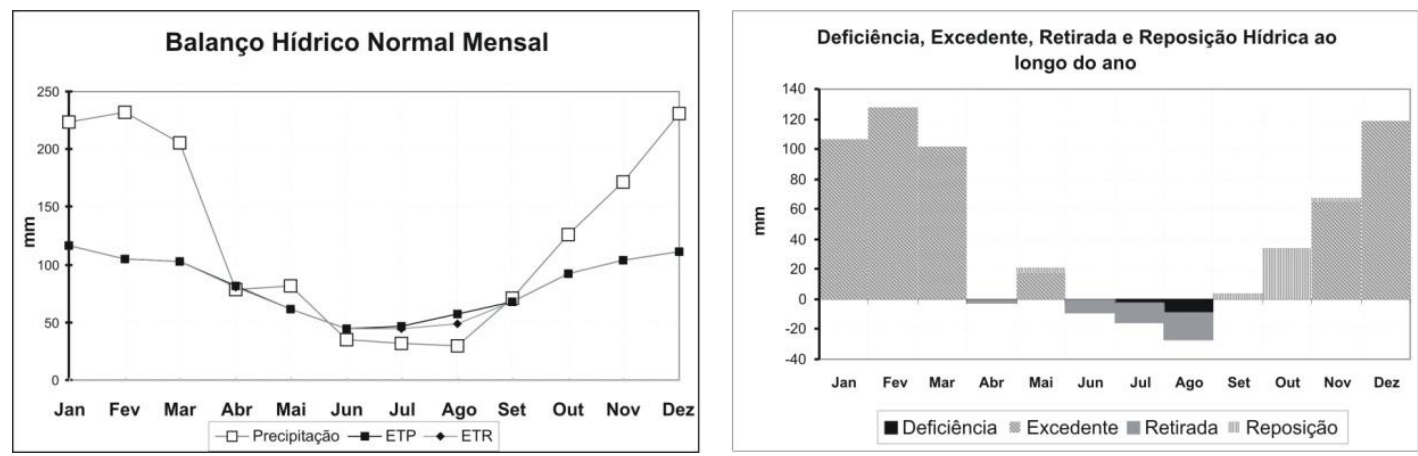

Figura 14 - Distribuição da precipitação e dos valores médios mensais de temperatura do ar e evapotranspiração (esquerda) e média mensal de deficiência, excedente, retirada e reposição hídrica (direita), entre 1982 e 1995, na estação meteorológica de Analândia.

A análise do balanço hídrico para a estação de Botucatu (Tabela 4 e Figuras 15 e 16), no período de 1982 a 1995, aponta a ocorrência de dois meses de deficiência hídrica, porém, somente no mês de agosto ocorre uma pequena retirada hídrica do sistema. A reposição da deficiência hídrica e da retirada observadas ocorre com as chuvas do mês de setembro. Ainda de acordo com a tabela 4, o excedente hídrico total médio para o período é de $615,1 \mathrm{~mm}$.

Tabela 4

Temperatura do ar e pluviometria média mensal e extrato do balanço hídrico médio mensal, entre 1982 e 1995, na estação meteorológica de Botucatu.

\begin{tabular}{cccccccc}
\hline Meses & $\begin{array}{c}\mathbf{T} \\
\text { oC }\end{array}$ & $\begin{array}{c}\mathbf{P} \\
\mathbf{m m}\end{array}$ & $\begin{array}{c}\text { ETP } \\
\text { Thornthwaite } \\
\mathbf{1 9 8 2 - 1 9 9 5}\end{array}$ & $\begin{array}{c}\text { ARM } \\
\mathbf{m m}\end{array}$ & $\begin{array}{c}\text { ETR } \\
\mathbf{m m}\end{array}$ & $\begin{array}{c}\text { DEF } \\
\mathbf{m m}\end{array}$ & $\begin{array}{c}\text { EXC } \\
\mathbf{m m}\end{array}$ \\
\hline Jan & 22,1 & 235,6 & 107,14 & 100,00 & 107,1 & 0,0 & 128,5 \\
Fev & 22,2 & 211,8 & 95,44 & 100,00 & 95,4 & 0,0 & 116,4 \\
Mar & 21,5 & 214,0 & 94,29 & 100,00 & 94,3 & 0,0 & 119,7 \\
Abr & 20,1 & 85,7 & 74,94 & 100,00 & 74,9 & 0,0 & 10,7 \\
Mai & 18,1 & 103,2 & 58,77 & 100,00 & 58,8 & 0,0 & 44,5 \\
Jun & 16,3 & 71,7 & 43,72 & 100,00 & 43,7 & 0,0 & 27,9 \\
Jul & 16,2 & 33,7 & 44,54 & 89,68 & 44,0 & 0,6 & 0,0 \\
Ago & 17,4 & 36,0 & 53,02 & 75,64 & 50,0 & 3,0 & 0,0 \\
Set & 17,9 & 89,6 & 57,48 & 100,00 & 57,5 & 0,0 & 7,7 \\
Out & 19,9 & 118,9 & 78,29 & 100,00 & 78,3 & 0,0 & 40,6 \\
Nov & 21,3 & 136,6 & 92,17 & 100,00 & 92,2 & 0,0 & 44,4 \\
Dez & 21,6 & 175,9 & 101,26 & 100,00 & 101,3 & 0,0 & 74,7 \\
\hline TOTAIS & 234,4 & 1512,6 & 901,06 & 1165 & 897,5 & 3,6 & 615,1 \\
\hline MÉDIAS & 19,5 & 126,1 & 75,09 & 97,1 & 74,8 & 0,3 & 51,3 \\
\hline & & & & & & &
\end{tabular}



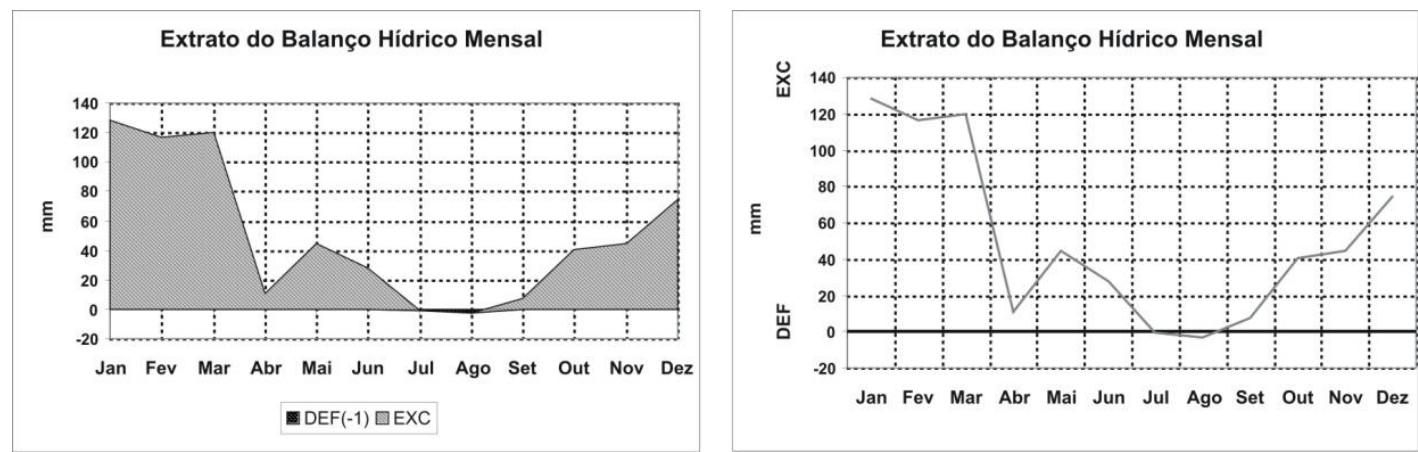

Figura 15 - Extrato do balanço hídrico médio mensal entre 1982 e 1995 na estação meteorológica de Botucatu.
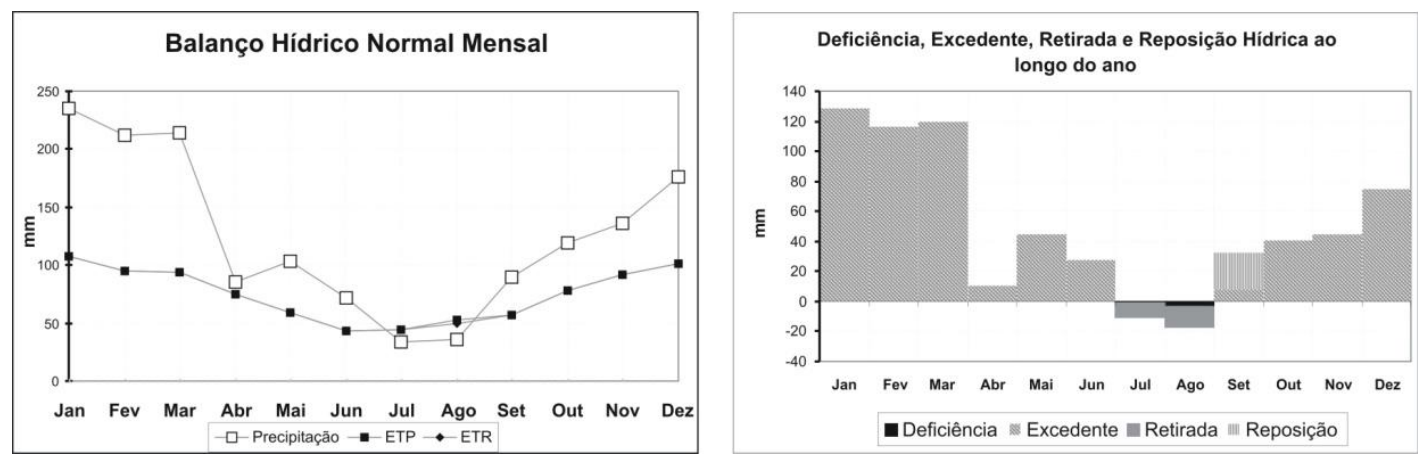

Figura 16 - Distribuição de precipitação e dos valores médios mensais de temperatura do ar e evapotranspiração (esquerda) e média mensal de deficiência, excedente, retirada e reposição hídrica (direita), entre 1982 e 1995, na estação meteorológica de Botucatu.

A tabela 5 mostra que a estação meteorológica de Piraju apresenta excedente hídrico total médio de 593,6 mm. Quando se analisa as reposições e retiradas do excedente hídrico, como mostra as figuras 17 e 18, pode-se concluir que nessa estação é onde se encontra a situação mais favorável para o balanço hídrico das áreas de afloramento do SAG e, assim, para as taxas de recarga do SAG,. A reposição hídrica utiliza apenas parte da precipitação do mês de setembro devido aos índices de retirada hídrica mínimos (Tabela 5 e Figura 18).

Esses resultados do balanço hídrico regional mostram que a porção sul da faixa de afloramentos do SAG é favorável a taxas mais elevadas de recarga, se comparado às zonas central e norte desta faixa (Tabela 6). Entretanto, devido à complexidade que o cálculo da reserva ativa exigiria para estimativas regionalizadas, foi considerada a média de precipitação anual, nos anos de 1982 a 1995 (1570 mm/ano), para toda zona de recarga do sistema aquífero no estado de São Paulo.

Por sua vez, para a estimativa da reserva ativa, foi utilizada a média excedente da pluviometria anual, que contribuiu para a recarga anual, ou seja, correspondente a nove meses de contribuição, perfazendo um volume total médio de $604 \mathrm{~mm} /$ ano (Tabela 6). Considerando o total de $4 \%$ do excedente hídrico médio, referente ao balanço hídrico no período de 1982 a 1995, e a área de recarga do SAG em território paulista de $18400 \mathrm{~km}^{2}$, obteve-se a reserva ativa de $4,4 \times 10^{8} \mathrm{~m}^{3} /$ ano 
Tabela 5

Temperatura do ar e pluviometria média mensal e extrato do balanço hídrico médio mensal, entre 1982 e 1995, na estação meteorológica de Piraju.

\begin{tabular}{cccccccc}
\hline Meses & oC & $\begin{array}{c}\mathbf{P} \\
\mathbf{m m}\end{array}$ & $\begin{array}{c}\text { ETP } \\
\text { Thornthwaite } \\
\mathbf{1 9 8 2 - 1 9 9 5}\end{array}$ & $\begin{array}{c}\text { ARM } \\
\mathbf{m m}\end{array}$ & $\begin{array}{c}\text { ETR } \\
\mathbf{m m}\end{array}$ & $\begin{array}{c}\text { DEF } \\
\mathbf{m m}\end{array}$ & $\begin{array}{c}\text { EXC } \\
\mathbf{m m}\end{array}$ \\
\hline Jan & 24,0 & 239,6 & 124,89 & 100,00 & 124,9 & 0,0 & 114,7 \\
Fev & 24,0 & 194,8 & 109,75 & 100,00 & 109,8 & 0,0 & 85,0 \\
Mar & 23,3 & 162,8 & 109,20 & 100,00 & 109,2 & 0,0 & 53,6 \\
Abr & 21,6 & 109,3 & 83,99 & 100,00 & 84,0 & 0,0 & 25,3 \\
Mai & 19,0 & 115,0 & 61,36 & 100,00 & 61,4 & 0,0 & 53,7 \\
Jun & 16,6 & 86,0 & 41,41 & 100,00 & 41,4 & 0,0 & 44,6 \\
Jul & 16,4 & 50,2 & 41,41 & 100,00 & 41,4 & 0,0 & 8,8 \\
Ago & 17,4 & 36,4 & 48,88 & 88,26 & 48,1 & 0,7 & 0,0 \\
Set & 18,8 & 98,5 & 59,54 & 100,00 & 59,5 & 0,0 & 27,2 \\
Out & 21,1 & 132,0 & 85,19 & 100,00 & 85,2 & 0,0 & 46,8 \\
Nov & 22,7 & 146,1 & 102,97 & 100,00 & 103,0 & 0,0 & 43,1 \\
Dez & 23,3 & 207,4 & 116,68 & 100,00 & 116,7 & 0,0 & 90,7 \\
\hline TOTAIS & 248,1 & 1578,1 & 985,27 & 1188 & 984,5 & 0,7 & 593,6 \\
\hline MÉDIAS & 20,7 & 131,5 & 82,11 & 99,0 & 82,0 & 0,1 & 49,5 \\
\hline
\end{tabular}
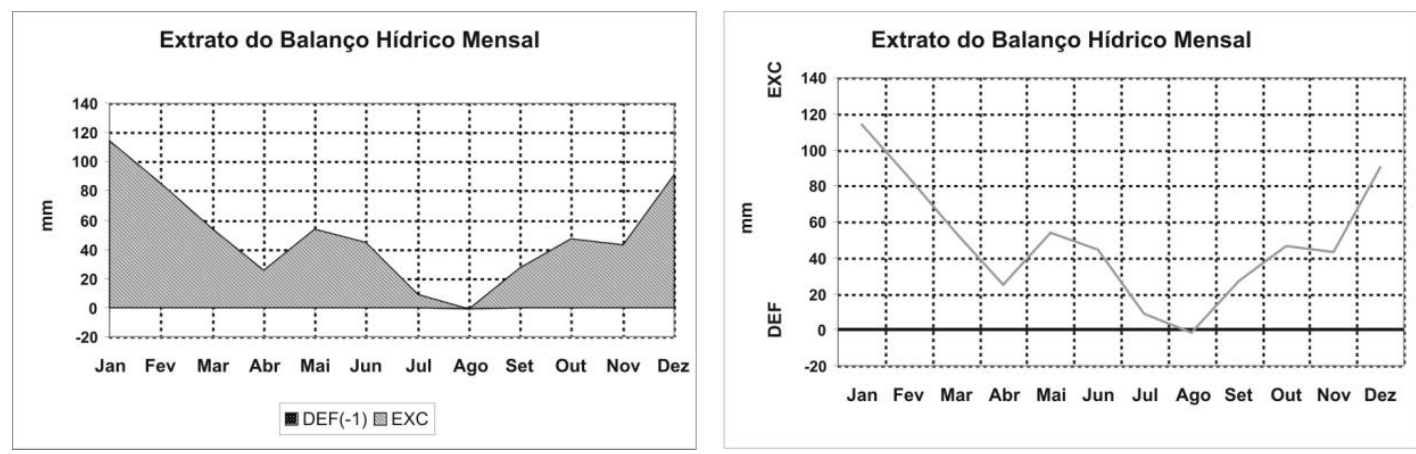

Figura 17 - Extrato do balanço hídrico médio mensal, entre 1982 e 1995, na estação meteorológica de Piraju.
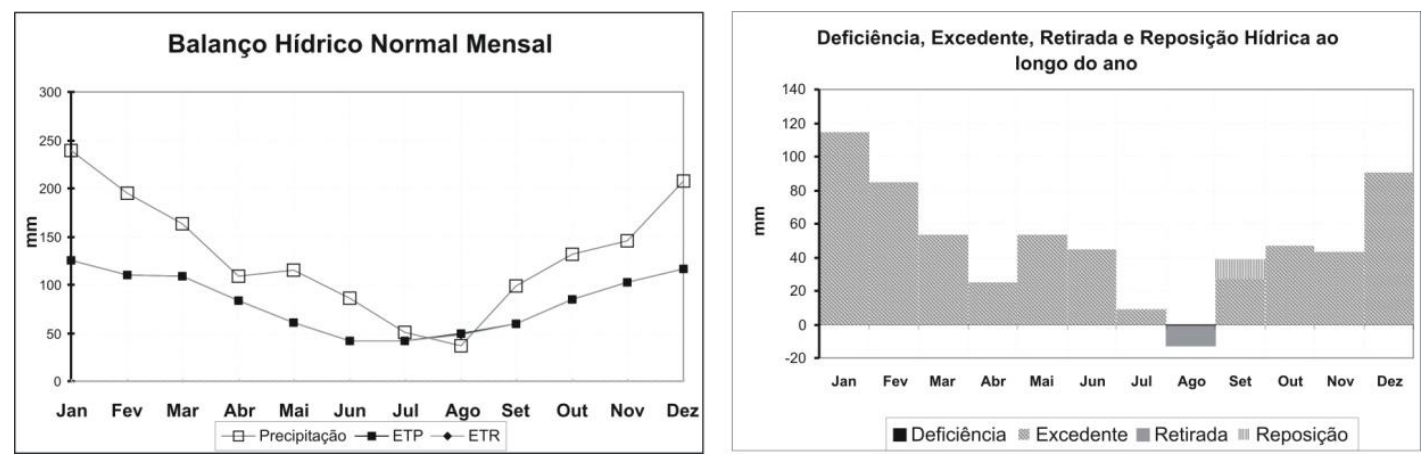

Figura 18 - Distribuição de precipitação e dos valores médios mensais de temperatura do ar e evapotranspiração (esquerda) e média mensal de deficiência, excedente, retirada e reposição hídrica (direita), entre 1982 e 1995, na estação meteorológica de Piraju. 
Tabela 6

\section{Síntese dos resultados para temperatura do ar média e pluviometria total e extrato do balanço hídrico médio total, entre 1982 e 1995, na estações meteorológicas da área de estudo.}

\begin{tabular}{lccccc}
\hline \multicolumn{1}{c}{ Estação } & T $\mathbf{~} \mathbf{C}$ (média) & P (mm) & ARM (mm) & DEF (mm) & EXC $(\mathbf{m m})$ \\
\hline Nuporanga & 21,6 & 1685,9 & 960 & 42,4 & 700,1 \\
Santa Rita do Passo Quatro & 21,4 & 1552,2 & 986 & 36,9 & 571,8 \\
Analândia & 20,9 & 1517,5 & 1086 & 11,6 & 537,7 \\
Botucatu & 19,5 & 1512,6 & 1165 & 3,6 & 615,1 \\
Piraju & 20,7 & 1578,1 & 1188 & 0,7 & 593,6 \\
\hline \multicolumn{1}{c}{ Média Geral } & $\mathbf{2 0 , 8}$ & $\mathbf{1 5 6 9 , 3}$ & $\mathbf{1 0 7 7 , 0}$ & $\mathbf{1 9 , 0}$ & $\mathbf{6 0 3 , 7}$ \\
\hline
\end{tabular}

\section{CONSIDERAÇÕES FINAIS}

Santos (2009) destaca que boa parte do abastecimento de água do território paulista é feito a partir de captação das águas subterrâneas na região da Bacia Sedimentar do Paraná (cerca de $70 \%$ do total consumido), e que apenas a produção do SAG atinge $43 \%$ do volume diário explorado. Nesse contexto, é crescente a preocupação das instituições com a gestão dos recursos hídricos subterrâneos, principalmente no tocante ao uso sustentável das águas do SAG.

Neste estudo verificou-se que o levantamento, a sistematização, o tratamento e a análise dos dados de pluviosidade e temperatura do ar, atributos fundamentais na análise dos climas, conduziram ao maior e melhor conhecimento dos fatores ligados à potencialidade em recursos hídricos subterrâneos da área de afloramentos do SAG no estado de São Paulo.

Os resultados do balanço hídrico regional mostram que a porção sul da faixa de afloramentos do SAG apresenta taxas mais elevadas de recarga, se comparada às porções central e norte desta faixa. Nessa região, verificou-se a melhor distribuição das chuvas ao longo dos anos amostrados, temperaturas do ar máximas médias para os meses mais quentes acima de 22 ${ }^{\circ} \mathrm{C}$, médias superiores a $30 \mathrm{~mm}$ de chuva nos meses mais secos e temperaturas médias mínimas menores que $18^{\circ} \mathrm{C}$.

As taxas pluviométricas na área de afloramento das formações geológicas constituintes do SAG são da ordem de 1400 mm/ano a 1600 mm/ano, com média para o período levantado de 1570 $\mathrm{mm} / \mathrm{ano}$, apresentando informações concordantes com outros estudos para a classificação climática estabelecidas para a área de estudo. A estimativa, com base nesses dados, do excedente hídrico que contribui para a recarga do aquífero, atingiu um volume total médio de $604 \mathrm{~mm} / \mathrm{ano}$.

Dessa forma, a reserva ativa calculada para o SAG é de aproximadamente $4,4 \times 10^{8} \mathrm{~m}^{3} /$ ano. Considerando os dados mais atuais de levantamentos populacionais, referentes ao censo de 2007, essa reserva subterrânea é responsável pelo abastecimento direto de uma população aproximada de 5 milhões de habitantes (consumidores efetivos). 


\section{REFERÊNCIAS}

.ARAÚJO, L. M., FRANÇA, A. B., POTTER, P. E. Aquífero Gigante do Mercosul no Brasil, Argentina, Uruguai e Paraguai: Mapas Hidrogeológicos das formações Botucatu, Pirambóia, Rosário do Sul, Buena Vista, Missiones e Taquarembó. Curitiba, Geociências, UFPR, 1995, 10p.

.CAETANO-ChANG, M. R. A Formação Pirambóia no centro-leste do Estado de São Paulo. Concurso (Livre-Docente) - Instituto de Geociências e Ciências Exatas, Universidade Estadual Paulista, Rio Claro, 1997.

.CAETANO-CHANG, M. R.; WU, F.T. Arenitos flúvio-eólicos da porção superior da Formação Pirambóia no centro-leste paulista. Revista Brasileira de Geociências, v. 36, p. 296-304, 2006.

.CHANG, H. K. Uso Atual e Potencial do Aquífero Guarani - Brasil. In: ARGENTINA/BRASIL/PARAGUAI/URUGUAI/GEF/BANCO/MUNDIAL/OEA. Proteção ambiental e gerenciamento sustentável integrado do Aquífero guarani. Atividade 3b: relatório final. Brasil, 2001. 54p.

.DEPARTAMENTO DE ÁGUAS E ENERGIA ELÉTRICA. Sistema de Informações para Gerenciamento de Recursos Hídricos do Estado de São Paulo. São Paulo: DAEE, SP, dados históricos de 1982 a 1995.

.DEPARTAMENTO DE ÁGUA E ENERGIA ELÁTRICA DO ESTADO DE SÃO PAULO; INSTITUTO GEOLÓGICO; SERVIÇO GEOLÓGICO DO BRASIL. Mapa de águas subterrâneas do Estado de São Paulo em 1:1.000.000. São Paulo, DAEE/IG-SMA/IPT/CPRM, 2005, CD-ROM.

.FUNDAÇÃO PARA O INCREMENTO DA PESQUISA E APERFEIÇOAMENTO INDUSTRIAL. Relatório técnico do Projeto de Gestão da Quantidade de Águas Subterrâneas. Ribeirão Preto, SP: FIPAI, 1996. 43p.

.GRAHAM, P., MACLEAN, L., MEDINA, D., PATWARDHAN, A., VASARHELYI, G. The role of water balance modelling in the transition to low impact Development. Water Quality Resource Journal, v. 39, n. 4, p. 331-342, 2004.

.HIRATA, R.; GASTMANS, D.; CRUZ, J. S.; ARAGUÁS, L.; SOARES, P. C.; FACCINI, U. F.; VIVES, L. Modelo Conceitual e Funcionalidades do Sistema Aquífero Guarani. In: II Congresso Aqüífero Guarani/Workshops. Memória... Ribeirão Preto: IG - Institulo Geológico de São Paulo. LEBAC/UNESP, pp 29-32, 2008.

.LABORATÓRIO DE ESTUDOS DE BACIAS. Estudo de viabilidade técnico-econômica de abastecimento da região metropolitana de São Paulo pelo Aquífero Guarani. Informe técnico: LEBAC/UNESP, 2004.

. PERROTTA, M.M.; SALVADOR, E.D.; LOPES, R.C.; D'AGOSTINO, L.Z.; PERUFFO, N.; GOMES, S.D.; SACHS, L.L.B.; MEIRA, V.T.; GARCIA, M.G.M.; LACERDA FILHO, J.V. 2005. Mapa Geológico do Estado de São Paulo, escala 1:750.000. Programa Geologia do Brasil - PGB: CPRM, São Paulo, 2005. (1) CD.

.REBOUÇAS, A.C. Recursos hídricos da Bacia do Paraná. Tese (Livre Docência). Instituto de Geociências, Universidade de São Paulo. São Paulo 1976.

.ROCHA, G. O grande manancial do Cone Sul. Estudos Avançados, USP. Vol.30, p.191-212, 1997.

.ROLIM, G. S.; SENTELHAS, P. C.; BARBIERI, V. Planilhas no ambiente EXCEL TM para os cálculos de balanços hídricos: normal, sequencial, de cultura e de produtividade real e potencial. Revista Brasileira de Agrometeorologia. Santa Maria, v. 6, n. 1, p133-137, 1998.

.ROLIM, G. S.; CAMARGO, M. B. P.; LANIA, D. G.; MORAES, J. F. L. Classificação climática de Köppen e de Thornthwaite e sua aplicabilidade na determinação de zonas agroclimáticas para o estado de São Paulo. In: Bragantia vol.66 no.4 Campinas, 2007.

.SANTOS, M. M. Avaliação hidrogeológica para determinação da vulnerabilidade natural do Aquífero freático em área selecionada na cidade de Londrina (PR). 
Dissertação (Mestrado). Instituto de Geociências e Ciências Exatas, Universidade Estadual Paulista, Rio Claro, 2005. 130p.

.SANTOS, M. M. Gerenciamento de recursos hídricos subterrâneos: uso atual e potencial do Sistema Aquífero Guarani no Estado de São Paulo. Tese (Doutorado). Instituto de Geociências e Ciências Exatas, Universidade Estadual Paulista, Rio Claro, 2009. $224 p$.

.SETZER, J. Atlas Climático e Ecológico do Estado de São Paulo. São Paulo: Comissão Interestadual da Bacia Paraná-Uruguai, 1966. 186 p.

.SOARES, P. C. O Mesozóico gondwânico no Estado de São Paulo. Tese (doutorado em geologia). Faculdade de Filosofia Ciências e Letras de Rio Claro - SP, 1973.

.SOARES, P. C. Divisão estratigráfica do Mesozóico no Estado de São Paulo. Revista Brasileira de Geociências, São Paulo, 5 (4): p. 229 - 251, 1975.

.SINELLI, O.; DAVINO A.; SOUZA A.; GONÇALVES N.M.M.; TEIXEIRA, J. Hidrogeologia da região da região de Ribeirão Preto (SP). In: ABAS, Congresso Brasileiro de Águas Subterrâneas, 1, Recife, Anais... São Paulo, v.2, p.441-449, 1987.

.Sinelli, O.; ALENCASTRE, C. E.; WENDLAND, E.; SILVA, G. P.; ARTUZO, M. A. S.; FINOTTI, P. Plano de Ação Estratégico para a Gestão do Sistema Aquífero Guarani na Área Piloto de Ribeirão Preto. In: II Congresso Aqüífero Guarani/Workshops. Memória... Ribeirão Preto: IG - Institulo Geológico de São Paulo. LEBAC/UNESP, pp 31-43, 2008.

.THORNTHWAITE, C.W. e MATHER, J.R. The water balance. Publications in climatology. New Jersey: Drexel Institute of Technology, v.8, 1955, 104 p.

.VELÁSQUEZ, L. N. M. Efeitos da urbanização sobre o sistema hidrológico: Aspectos da recarga no aqüífero freático e escoamento superficial - área piloto: Sub-bacias Sumaré e Pompéia, Município de São Paulo. Tese (Doutorado) - Instituto de Geociências, Universidade de São Paulo. São Paulo, 1996. 